\title{
BMJ Open Characteristics of stakeholder involvement in systematic and rapid reviews: a methodological review in the area of health services research
}

\author{
Jonas Feldmann, Milo Alan Puhan, Margot Mütsch
}

To cite: Feldmann J, Puhan MA, Mütsch M. Characteristics of stakeholder involvement in systematic and rapid reviews: a methodological review in the area of health services research. BMJ Open 2019;9:e024587. doi:10.1136/ bmjopen-2018-024587

- Prepublication history and additional material for this paper are available online. To view these files, please visit the journal online (http://dx.doi. org/10.1136/bmjopen-2018024587).

Received 11 June 2018 Revised 10 July 2019 Accepted 17 July 2019

\section{Check for updates}

(c) Author(s) (or their employer(s)) 2019. Re-use permitted under CC BY-NC. No commercial re-use. See rights and permissions. Published by BMJ.

Epidemiology, Biostatistics and Prevention Institute, University of Zurich, Zurich, Switzerland

Correspondence to Dr Margot Mütsch; margot.muetsch@uzh.ch

\section{ABSTRACT}

Objective Engaging stakeholders in reviews is considered to generate more relevant evidence and to facilitate dissemination and use. As little is known about stakeholder involvement, we assessed the characteristics of their engagement in systematic and rapid reviews and the methodological quality of included studies. Stakeholders were people with a particular interest in the research topic. Design Methodological review.

Search strategy Four databases (Medline, Embase, Cochrane database of systematic reviews, databases of the University of York, Center for Reviews and Dissemination (CRD)) were searched based on an a priori protocol. Four types of reviews (Cochrane and non-Cochrane systematic reviews, rapid and CRD rapid reviews) were retrieved between January 2011 and October 2015, pooled by potential review type and duplicates excluded. Articles were randomly ordered and screened for inclusion and exclusion criteria until 30 reviews per group were reached. Their methodological quality was assessed using AMSTAR and stakeholder characteristics were collected.

Results In total, 57822 deduplicated citations were detected with potential non-Cochrane systematic reviews being the biggest group (56 986 records). We found stakeholder involvement in 13\% (4/30) of Cochrane, $20 \%(6 / 30)$ of non-Cochrane, $43 \%(13 / 30)$ of rapid and $93 \%(28 / 30)$ of CRD reviews. Overall, $33 \%$ (17/51) of the responding contact authors mentioned positive effects of stakeholder involvement. A conflict of interest statement remained unmentioned in 40\% (12/30) of non-Cochrane and in $27 \%(8 / 30)$ of rapid reviews, but not in Cochrane or CRD reviews. At most, half of non-Cochrane and rapid reviews mentioned an a priori study protocol in contrast to all Cochrane reviews.

Conclusion Stakeholder engagement was not general practice, except for CRD reviews, although it was more common in rapid reviews. Reporting factors, such as including an a priori study protocol and a conflict of interest statement should be considered in conjunction with involving stakeholders.

\section{INTRODUCTION}

Evidence synthesis remains a rapidly growing field. There are different methodological approaches and formats depending on the
Strengths and limitations of this study

- A systematic approach to assess stakeholder engagement in systematic and rapid reviews was used to fill the gap and to provide an overview of the current situation.

- The different review types were able to inform on stakeholder involvement and pointed to potential improvements.

- With the scope of this study being restricted to health services research we intended to focus on a best-case approach where the context is considered most important and therefore, stakeholder involvement might be most regularly, but the overall findings might not be applicable beyond this domain.

- The majority of studies were from high-income countries limiting the generalisability beyond this setting.

- The perception and the reporting of stakeholder involvement might be influenced by the lack of a uniform definition of stakeholders and depend on the criteria used.

research question and the intended use of the review, such as scoping, systematic or rapid reviews as well as realist syntheses, policy briefs and health technology assessments (HTAs). We will focus on full systematic reviews as a well-established review type in healthcare and on rapid reviews as an emerging one. A traditional full systematic review is a review that 'attempts to collate all empirical evidence and that fits prespecified eligibility criteria in order to answer a specific, usually narrow research question or intervention'. ${ }^{1}$ Within systematic reviews, Cochrane full systematic reviews were established as 'gold standard' in knowledge synthesis. A couple of studies compared Cochrane and non-Cochrane systematic reviews and found that the reporting of Cochrane systematic reviews was the most complete one, ${ }^{2}$ that they were less prone to bias due to greater transparency in reporting as well as due to the quality criteria 
used, such as the risk of bias assessment. ${ }^{3}$ Furthermore, Hopewell et al described that the inclusion of grey literature routinely performed in Cochrane systematic reviews limited publication bias and provided more conservative treatment effects compared with non-Cochrane systematic reviews without including grey literature. ${ }^{4}$

Rapid reviews are characterised by a less complex research question and aim to synthesise evidence within a shorter time period, with time frames ranging from 1 week to 9 months. ${ }^{56}$ They might, therefore, be prone to be of lower validity as a consequence of accelerating and streamlining the review process. ${ }^{5}$ However, in response to an increasing demand from stakeholders, rapid reviews are being performed more frequently than before. ${ }^{6}$ Only few formal definitions of different rapid reviews exist and few studies have examined their methodology. ${ }^{7}$ To cover the variety of rapid reviews we included rapid reviews listed in medical databases as well as other rapid reviews from the databases of the University of York, Center for Reviews and Dissemination (www.crd.york.ac.uk/CRDWeb), such as the Dare reviews (Database of Abstracts of Reviews of Effects) or HTAs (CRD rapid reviews). Rapid reviews target specific audiences including government policymakers, healthcare institutions, health professionals and patient associations and research questions are often tailored to these stakeholders ${ }^{89}$

Stakeholder as a very broad term may include anyone affected by an issue and/or anyone who can provide input on the topic. ${ }^{1011}$ Hence, not only decision makers, health professionals and their organisations are targeted, but also citizen or patients, other researchers and the media. Involving stakeholders in health services research might be possible at all stages of systematic or rapid reviews and this is often referred to as co-production. Thus, stakeholder engagement aims participatory research and might direct the research question, define the scope and context of the review as well as contribute to the literature search, the evidence synthesis and interpretation and might facilitate dissemination and use. Therefore, it enhances the relevance of findings for policy and practice and contributes to the sustainability of health systems. ${ }^{12-14}$ We especially focused on stakeholder involvement among health services research. This embraced 'the multidisciplinary field of scientific studies regarding social, financing and personal factors, organisational structures and processes, health technologies, and how these factors affect access to, the quality and cost of healthcare, and ultimately, our health and well-being, ${ }^{15}$ Here, we considered the context of conducted studies and dissemination issues as most important, and we expected health services research to be the research field where stakeholders were involved most regularly.

\section{Study aim}

To date, little is known about the extent of stakeholder engagement in systematic and rapid reviews and there have been few efforts to directly report the specific effects regarding their involvement. We consider this information to be relevant for integrated knowledge translation, the dissemination and acceptance of systematic and rapid reviews in policy and practice. We focused on systematic and rapid reviews as they represent different types of evidence synthesis and are well-established in research and practice. In addition, reviews needed to belong to the area of health services research as an established field for systematic and rapid reviews as well as a best-case sample with a considerable extent of stakeholder involvement. We aimed to assess the extent and characteristics of stakeholder engagement in published systematic and rapid reviews and to specifically determine reporting characteristics.

\section{METHODS \\ Study design}

Based on the prespecified protocol this methodological review was performed to assess characteristics and reporting of stakeholder engagement in random samples of systematic and rapid reviews in the field of health services research (online supplementary file S1). A total of four types of reviews, two groups of each, systematic and rapid reviews, were assessed as they were considered to exhibit potentially differences in stakeholder involvement. This included Cochrane systematic reviews, non-Cochrane systematic reviews, rapid reviews and rapid reviews of the databases of the University of York, CRD rapid reviews. For the reporting of this study the Preferred Reporting Items for Systematic Reviews and Meta-Analyses (PRISMA) checklist was used (online supplementary file $S 2)$.

\section{Search strategy and screening}

For systematic reviews, we searched the Cochrane database of systematic reviews for articles including the term 'systematic review' in their title or abstract (Cochrane systematic reviews) and EBSCO Medline and Embase with excluding the term 'Cochrane' in title or abstract (non-Cochrane systematic reviews). Rapid reviews were searched in EBSCO Medline and Embase and in the databases of the University of York, CRD rapid reviews ( www.crd.york.ac.uk/CRDWeb). Sample search strategies are depicted in online supplementary files S3a and S3b. We included studies published between January 2011 and December 2015 without language restriction. Our search was completed on 22 October 2015 and therefore, the search results for 2015 did not cover the whole year. All results were pooled by review type and duplicates were excluded based on authors, journal and publication year. For each of the four lists of potential study types, each reference was given a unique random number using the sample() function available in $\mathrm{R} .{ }^{16}$ Each list was then sorted by the random number, and the articles were screened in order for inclusion and exclusion criteria by two reviewers until a total of 30 studies were reached per group (JF and MM tested their consistency in assessing the inclusion and exclusion criteria for about 10 different 
studies and MM checked the assignment for about half of the study sample). Full text screening was performed to ensure the decision. One review author (JF) performed data extraction, supervised and spot-checked by a second researcher (MM). Disagreements were resolved by consensus.

\section{Sample size and selection of review groups}

As rapid reviews were often targeted to specific audiences, ${ }^{89}$ they were expected to involve stakeholders to a greater extent. We estimated a proportion of stakeholder involvement of 0.70 for rapid reviews and of 0.25 for systematic reviews, which resulted in a minimal expected difference of 0.45 . For a two group-comparison, rapid and systematic reviews, with $\mathrm{n}=25$ per group there will be an estimated power of 0.88 and an alpha of 0.023 . To account for a potential subgroup analysis, we included a sample of $n=30$ reviews per group, with four review groups (Cochrane and non-Cochrane systematic reviews, rapid and CRD rapid reviews). This resulted in an overall sample of 120 studies.

\section{Inclusion and exclusion criteria}

We included reviews targeting health services research as defined by Lohr ${ }^{15}$ : "Health services research is the multidisciplinary field of scientific investigation that studies how social factors, financing systems, organizational structures and processes, health technologies, and personal behaviors affect access to health care, the quality and cost of health care, and ultimately, our health and well-being. Its research domains are individuals, families, organizations, institutions, communities, and populations". Therefore, we included HTAs (eg, rapid reviews as part of HTAs) targeting effectiveness as well as meta-analyses and systematic reviews for effectiveness and utility, reviews of pharmaceutical trials under everyday conditions, reviews of basic research in care-related fields, reviews of quality research or of methodological developments in the field of health services research, reviews about the development and application of new technologies (ehealth) and the implementation of knowledge into clinical practice. We excluded reviews that focused exclusively on economic or cost analyses, performed a narrative review, an overview of reviews or a protocol of a systematic review in order not to mix so different methodological approaches. The following study types were also excluded: reviews of efficacy studies without assessing the quality of life, reviews including clinical efficacy trials phase I-III, epidemiological reviews to assess determinants or risk factors, non-human studies, establishment of databases or registries, reviews with unclear design or description of the intervention.

\section{Data extraction}

Stakeholders were defined as people with a particular interest in the research topic (but were not members of the primary research team). ${ }^{10}{ }^{17}$ We evaluated any kind of stakeholder involvement and recorded different groups of stakeholders: institutional healthcare providers, representatives of hospitals or community services, patients/ consumers, participants of government agencies and healthcare policymakers at Federal, State and local levels, associations of health professionals and researchers (if not members of the primary study team). If available, we identified their fields and stages of involvement as well as their contribution to the study. This included all review steps, such as formulating the research question(s), determining study characteristics, contributing to the writing of the protocol, participating within the review process with searching, screening, data extraction, synthesising, interpreting the study results and/or establishing recommendations. In addition, we extracted the following data: institution where the review was performed, contact details of the corresponding author, the type of intervention, study setting, characteristics of the population (sample size, age range, sex), funding, declared conflict of interest, year of publication. The methodological quality of included articles was assessed using the AMSTAR tool, a measurement tool for the assessment of the methodological quality of systematic reviews. ${ }^{18}$ Where available, our rating was compared with an already existing one from the 'health evidence' or 'health systems evidence' platforms. ${ }^{19}{ }^{20}$ Both quality ratings were then categorised as strong $(\geq 8)$, moderate $(4-7)$ or weak $(<4)$. In the absence of a quality assessment tool for rapid reviews, we used AMSTAR also for rapid reviews, being aware that this might result in lower rating scores due to abbreviated procedures. In addition, the use of the PRISMA checklist was recorded when mentioned in the articles. ${ }^{21}$ AMSTAR ratings are presented as online supplementary file S4, study characteristics as online supplementary file S5.

To ascertain stakeholder engagement as well as to assess the extent or stages of their involvement, preformulated questions were sent by email to the contact authors of the included articles. We asked them, if there had been any stakeholder involvement (yes or no) and if so, to specify the number of stakeholders, the stages of involvement and their self-assessed estimation of the effect of stakeholder engagement on the review outcome. In case of missing responses, one reminder was sent.

\section{Patient and Public involvement}

None involved.

\section{RESULTS}

Our search identified 57822 citations remaining after exclusion of duplicates. Although, not all of these records will fulfil the inclusion criteria, such as for example, being designed as a systematic review, we assigned them as potential review group. For the screening step, the counts of the articles that needed to be screened to reach the final set of studies are depicted in figure $1 .{ }^{22-141}$ The excluded studies are presented in online supplementary table S1. 


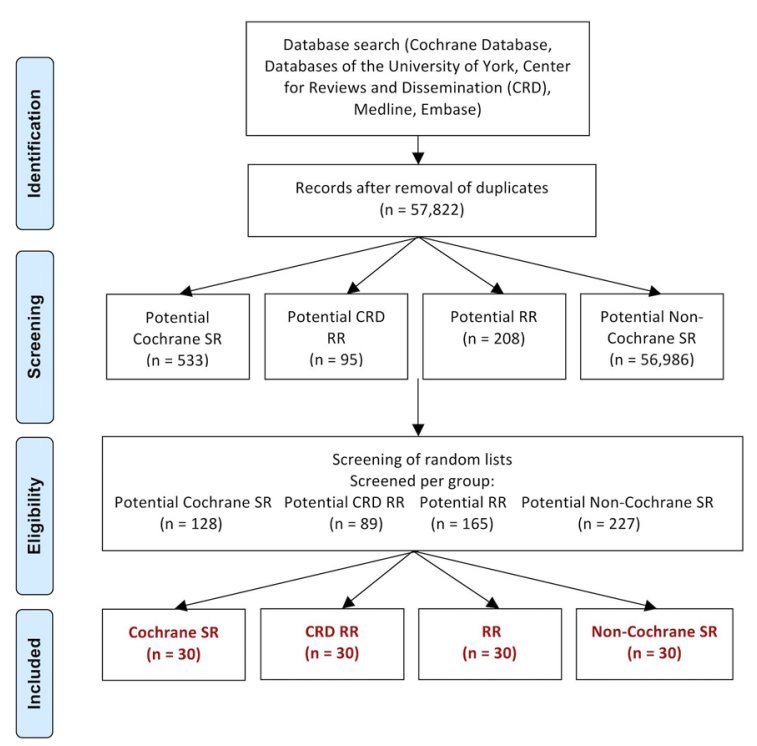

Figure 1 Flow diagram of study selection. CRD, databases of the University of York, Centre for Reviews and Dissemination; RR, rapid review; SR, systematic review.

Table 1 presents the characteristics of the included studies. Cochrane systematic reviews generally focused on the prevention and treatment of specific conditions, whereas $30 \%$ of non-Cochrane systematic reviews were categorised with a community-based topic, with a wide range of participants and possible outcomes and a broader range of study settings. Of note, $23 \%$ of each, rapid reviews and CRD rapid reviews, were categorised as health system intervention, because they focused on methodological questions or health quality research.

We detected noticeable differences when comparing the median AMSTAR scores: Cochrane systematic reviews and CRD rapid reviews showed higher median scores than non-Cochrane systematic reviews and rapid reviews. Where available, we also collected existing AMSTAR ratings from the 'health evidence' or 'health systems evidence' platforms. For 68\% (13/19 study ratings) we found a congruent classification as strong, moderate or weak, respectively (online supplementary file S4). In non-Cochrane reviews information about methodological specifications of included studies were often lacking. As an example, all 30 Cochrane systematic reviews (100\%) mentioned a pre-existing review protocol, whereas a high amount of non-Cochrane systematic reviews (59\%) and of rapid reviews $(43 \%)$ did not clarify whether there had been a protocol or not. Similarly, all 30 Cochrane systematic reviews and all but one CRD rapid reviews (97\%) included a conflict of interest statement, whereas $40 \%$ of non-Cochrane systematic reviews and $27 \%$ of rapid reviews lacked such a paragraph. All reviews were funded by national or international governmental or institutional sources. Only one rapid review reported the acceptance of additional funding from a pharmaceutical company.

Characteristics of the study population by type of included review are presented in online supplementary table S2.
Any stakeholder involvement was mentioned in 13\% of Cochrane systematic reviews, $20 \%$ of non-Cochrane systematic reviews, $43 \%$ of rapid reviews and $93 \%$ of CRD rapid reviews. Except for CRD rapid reviews, where the involvement of stakeholders was routinely reported in the methods or appendix section, about half of the stakeholder involvement was reported in the articles and the other half was confirmed via email by contact authors and remained unmentioned in the reviews. With $67 \%$ the email response rate was highest for rapid reviews. When comparing the amount of stakeholder involvement in different review topics, there were notable differences: the proportion of stakeholder involvement in reviews focusing on prevention or treatment of specific conditions was lower than in those targeting health system interventions. Interestingly, the proportion of stakeholder involvement has been quite constant between the years $2012(5 / 15$, $33 \%)$ and $2014(12 / 34,34 \%)$ even though the amount of rapid reviews has increased substantially (table 2 ). There was, however, a remarkable increase in the proportion of stakeholder involvement for the year 2015 (22/32, 69\%), but this was mostly due to the fact that a majority of CRD rapid reviews, which presented the highest proportion of stakeholder involvement, was indexed in 2015.

CRD rapid reviews turned out to have by far the highest proportion of reported stakeholder involvement. The types of stakeholders engaged were listed in the appendix of 26/30 articles, but it was not specified what they had specifically contributed to the review, for example, if their contribution had affected the final results and conclusions of the reviews (table 3). One author mentioned in the review that the reason for involving stakeholders was to understand the clinical perspective.

We detected stakeholder involvement in 43\% (13/30) of rapid reviews. In contrast to CRD rapid reviews, there was usually a small number of stakeholders engaged. They were involved at different phases, such as determining study characteristics, formulating the research question, within the review process in general, and less commonly in protocol writing, result synthesis and the interpretation of findings. One article involved stakeholder throughout all stages, in one case the phase of involvement was not specified. In total, $85 \%$ of the authors confirmed, that the stakeholders had significantly contributed to the review. Of these, $62 \%$ mentioned that involving stakeholders led to an increased impact of the review and enabled to focus on the needs of target groups, which made the review more relevant to for example, patients or policymakers. Stakeholders had commissioned one third of the rapid reviews or had asked for evidence. Only two of 13 authors $(15 \%)$ did not mention any substantial effect. In two cases one of the funding sources was involved as stakeholder.

We identified stakeholder involvement in 20\% (6/30) of non-Cochrane systematic reviews. In four cases the stakeholder involvement was confirmed via email, two articles mentioned the involvement of stakeholders. Only two types of stakeholders were reported: policymakers and researchers. If mentioned, all phases of 
Table 1 Characteristics of included reviews by review type

\section{Cochrane SR Non-Cochrane SR}

\begin{tabular}{llllll} 
& (\%) & (\%) & RR (\%) & CRD RR (\%) Total (\%) \\
\hline $\begin{array}{l}\text { Random sample } \\
\text { (\% of total per group) }\end{array}$ & $30(6)$ & $30(0.1)$ & $30(14)$ & $30(32)$ & $120(0.2)$
\end{tabular}

Geographic location of the corresponding author (\% of random sample)

\begin{tabular}{|c|c|c|c|c|c|}
\hline Africa & $2(7)$ & 0 & 0 & 0 & $2(2)$ \\
\hline Asia & $5(17)$ & $3(10)$ & $1(3)$ & 0 & $9(8)$ \\
\hline Australia & $3(10)$ & $5(17)$ & $2(7)$ & 0 & $10(8)$ \\
\hline Europe & $11(37)$ & $13(43)$ & $13(43)$ & $2(7)$ & $39(33)$ \\
\hline North America & $7(23)$ & $8(27)$ & $14(47)$ & $28(93)$ & $57(48)$ \\
\hline South America & $2(7)$ & $1(3)$ & 0 & 0 & $3(3)$ \\
\hline \multicolumn{6}{|l|}{ Thematic focus } \\
\hline Prevention & $11(37)$ & $5(17)$ & $4(13)$ & $7(23)$ & $27(23)$ \\
\hline Treatment & $18(60)$ & $14(47)$ & $15(50)$ & $16(53)$ & $63(53)$ \\
\hline Health system & $1(3)$ & $2(7)$ & $7(23)$ & $7(23)$ & $17(14)$ \\
\hline Community-based ${ }^{*}$ & 0 & $9(30)$ & $4(13)$ & 0 & $13(11)$ \\
\hline \multicolumn{6}{|l|}{ Funding } \\
\hline Governmental, institutional or WHO & $30(100)$ & $30(100)$ & $30(100)$ & $30(100)$ & $120(100)$ \\
\hline Additional funding by company & 0 & 0 & $1(3)$ & 0 & $1(1)$ \\
\hline \multicolumn{6}{|l|}{ Conflict of interest (COI) } \\
\hline Declared none & $21(70)$ & $15(50)$ & $19(63)$ & $29(97)$ & $84(70)$ \\
\hline COI declared & $9(30)$ & $3(10)$ & $3(10)$ & 0 & $15(13)$ \\
\hline Unmentioned & 0 & $12(40)$ & $8(27)$ & $1(3)$ & $21(18)$ \\
\hline \multicolumn{6}{|l|}{ Study protocol } \\
\hline Yes, mentioned in article & $30(100)$ & $5(17)$ & $4(13)$ & $1(3)$ & $40(33)$ \\
\hline Yes, mentioned in correspondence & 0 & $8(27)$ & $9(30)$ & 0 & $17(14)$ \\
\hline No, confirmed by correspondence & 0 & $2(7)$ & $4(13)$ & 0 & $6(5)$ \\
\hline Unmentioned & 0 & $15(50)$ & $13(43)$ & $29(97)$ & $57(48)$ \\
\hline \multicolumn{6}{|l|}{ AMSTAR rating } \\
\hline Median (range) & $11(7,11)$ & $7(3,11)$ & $4(2,10)$ & $8(5,11)$ & $8(2,11)$ \\
\hline
\end{tabular}

AMSTAR: measurement tool for the 'assessment of the methodological quality of systematic reviews', not applicable questions were not counted. Higher AMSTAR scores indicate higher quality.

*With exclusion of treatment or preventive interventions.

CRD, databases of the University of York, Center for Reviews and Dissemination; RR, rapid review;SR, systematic review.

involvement occurred about equally. A total $67 \%(4 / 6)$ study authors reported significant benefit from the stakeholders' contributions. One author mentioned that stakeholder supported the researchers to understand different perspectives of the problem, and 33\% (2/6) reported no effect. In one case, the stakeholder was involved as funding source.

Cochrane systematic reviews turned out to be the group with the smallest amount of stakeholder involvement. All stakeholder engagement was confirmed and specified by email. The types of stakeholders engaged were patients, caregivers, professional organisations and researchers. They were mostly involved for providing feedback during the review process, in one case they contributed in formulating the review question. One review involved stakeholders at all stages. A total of $50 \%(2 / 4)$ of the authors reported substantial benefit, the other $50 \%(2 / 4)$ reported no significant effect on study results or conclusions. Two authors had involved stakeholders to make the review more relevant for its target audience, one author claimed that stakeholders helped him to refine the research question. One author involved stakeholders to get direct consumer feedback before publishing the review. No stakeholders were involved in funding.

\section{DISCUSSION}

The involvement of stakeholders varies by review type. Our findings suggest that rapid reviews tend to involve stakeholders more than twice as frequently than systematic 
Table 2 General characteristics of stakeholder involvement (SI) by review type

\begin{tabular}{|c|c|c|c|c|c|}
\hline & $\begin{array}{l}\text { Cochrane SR } \\
(\%)(n=30)\end{array}$ & $\begin{array}{l}\text { Non-Cochrane SR } \\
(\%)(n=30)\end{array}$ & $\begin{array}{l}\mathrm{RR}(\%) \\
(\mathrm{n}=30)\end{array}$ & $\begin{array}{l}\text { CRD RR (\%) } \\
(n=30)\end{array}$ & $\begin{array}{l}\text { Total (\%) } \\
(\mathrm{N}=120)\end{array}$ \\
\hline SI mentioned in article & $2(7)$ & $2(7)$ & $6(20)$ & $28(93)$ & $38(32)$ \\
\hline SI only mentioned in correspondence & $2(7)$ & $4(13)$ & $7(23)$ & 0 & $13(11)$ \\
\hline Total SI & $4(13)$ & $6(20)$ & $13(43)$ & $28(93)$ & $51(43)$ \\
\hline \multicolumn{6}{|l|}{ SI per year } \\
\hline 2011 & $0 / 5(0)$ & $0 / 1(0)$ & $0 / 3(0)$ & $0 / 0(0)$ & $0 / 9(0)$ \\
\hline 2012 & $3 / 7(43)$ & $1 / 5(20)$ & $1 / 3(33)$ & $0 / 0(0)$ & $5 / 15(33)$ \\
\hline 2013 & $0 / 9(0)$ & $0 / 6(0)$ & $3 / 5(60)$ & $9 / 10(90)$ & $12 / 30(40)$ \\
\hline 2014 & $1 / 7(14)$ & $3 / 9(30)$ & $6 / 15(40)$ & $2 / 3(67)$ & $12 / 34(35)$ \\
\hline 2015 & $0 / 2(0)$ & 2/9 (22) & 3/4 (75) & $17 / 17(100)$ & 22/32 (69) \\
\hline \multicolumn{6}{|c|}{ Number of stakeholders involved per review (\% of SI) } \\
\hline 1 & $2(50)$ & $2(33)$ & $2(15)$ & 0 & $6(12)$ \\
\hline $2-4$ & $1(25)$ & $1(17)$ & $4(31)$ & $2(7)$ & $8(16)$ \\
\hline$>4$ & $1(25)$ & $3(50)$ & $4(31)$ & $26(93)$ & $34(67)$ \\
\hline Unspecified & 0 & 0 & $3(23)$ & 0 & $3(6)$ \\
\hline \multicolumn{6}{|c|}{ Types of stakeholders (multiple roles possible) (\% of SI) } \\
\hline Patients/consumers & $2(50)$ & 0 & $2(15)$ & $5(18)$ & $9(18)$ \\
\hline Professional organisations & $1(25)$ & 0 & 0 & $5(18)$ & $6(12)$ \\
\hline Caregivers & $2(50)$ & 0 & $3(23)$ & $23(82)$ & $28(55)$ \\
\hline Researchers & $1(25)$ & $3(50)$ & $2(15)$ & 0 & $6(12)$ \\
\hline Policymakers & 0 & $3(50)$ & $4(31)$ & $3(11)$ & $10(20)$ \\
\hline Unspecified & 0 & 0 & $2(15)$ & $4(14)$ & $6(12)$ \\
\hline \multicolumn{6}{|l|}{ Funding source $(\%$ of $\mathrm{SI})$} \\
\hline Governmental or institutional funding & $4(100)$ & $6(100)$ & $13(100)$ & $28(100)$ & $51(100)$ \\
\hline Funding source involved as stakeholder & 0 & $1(17)$ & $2(15)$ & 0 & $3(6)$ \\
\hline \multicolumn{6}{|c|}{ Thematic focus (\% per review type per topic) } \\
\hline Prevention & 0/11 (0) & $0 / 5(0)$ & $1 / 4(25)$ & 6/7 (86) & 7/27 (26) \\
\hline Treatment & 4/18 (22) & $3 / 14(21)$ & $6 / 15(40)$ & $16 / 16(100)$ & $29 / 63(46)$ \\
\hline Health system & $0 / 1(0)$ & $1 / 2(50)$ & $5 / 7(71)$ & 6/7 (86) & $12 / 17(71)$ \\
\hline Community-based & $0 / 0(0)$ & 2/9 (22) & $1 / 4(25)$ & $0 / 0(0)$ & $3 / 13(23)$ \\
\hline
\end{tabular}

CRD, databases of the University of York, Center for Reviews and Dissemination; RR, rapid review; SR, systematic review.

reviews. On average, they also involved a greater number of stakeholders per review. In addition, we detected considerable differences in the phases in which stakeholders were involved. Rapid reviews involved them at very early stages of the review process, such as determining the intentional study characteristics or formulating the research question. Furthermore, it seemed to be much more common for policymakers, who were the most frequent group of stakeholders involved in rapid reviews, or other stakeholder groups, to substantially contribute to rapid reviews than to systematic reviews.

Of note, the majority of rapid and non-Cochrane systematic review authors reported that the involved stakeholders had positive and considerable effects on the study results, making the review more relevant for the targeted audience. However, the minority of rapid and
non-Cochrane systematic review authors reporting no effect of stakeholder involvement on the review process, may illustrate that the stakeholders' contribution to non-Cochrane systematic reviews was seen as an additional and welcomed feature to the review, but not as a substantial part. This shows the importance that within and between review types an information and experiences exchange between researchers could benefit the stakeholder engagement.

A strength of this study is to provide an overview with its rather low amount of stakeholder engagement in the assessed review types despite known benefits regarding the use of evidence in policy and practice. With respect to the different procedures used by review types, the reported experiences of stakeholder engagement, for example, in rapid reviews, could further benefit and 
Table 3 Engagement characteristics of stakeholder involvement (SI) by review type

\begin{tabular}{|c|c|c|c|c|c|}
\hline & $\begin{array}{l}\text { Cochrane SR } \\
(\%)(n=30)\end{array}$ & $\begin{array}{l}\text { Non-Cochrane SR } \\
(\%)(\mathrm{n}=30)\end{array}$ & $\begin{array}{l}\mathrm{RR}(\%) \\
(\mathrm{n}=30)\end{array}$ & $\begin{array}{l}\text { CRD RR (\%) } \\
(\mathrm{n}=30)\end{array}$ & $\begin{array}{l}\text { Total (\%) } \\
(\mathrm{N}=120)\end{array}$ \\
\hline \multicolumn{6}{|l|}{ Stages of SI (multiple stages possible) (\% of SI) } \\
\hline Research question & $1(25)$ & $1(17)$ & $4(31)$ & 0 & $6(12)$ \\
\hline Study characteristics & 0 & 0 & $6(46)$ & 0 & $6(12)$ \\
\hline Protocol writing & 0 & $1(17)$ & $2(15)$ & 0 & $3(6)$ \\
\hline Review process & $3(75)$ & $1(17)$ & $5(38)$ & 0 & $9(18)$ \\
\hline Interpretation of findings & 0 & $1(17)$ & $1(8)$ & 0 & $2(4)$ \\
\hline Result synthesis & 0 & 0 & $2(15)$ & 0 & $2(4)$ \\
\hline Multiple or all stages & $1(25)$ & $2(33)$ & $1(8)$ & $28(100)$ & $32(63)$ \\
\hline Unspecified & 0 & $2(33)$ & $1(8)$ & 0 & $3(6)$ \\
\hline \multicolumn{6}{|l|}{ Reasons mentioned for SI (\% of SI) } \\
\hline Stakeholder commissioned/requested review & 0 & $1(17)$ & $4(31)$ & 0 & $5(10)$ \\
\hline To get consumer feedback & $1(25)$ & 0 & 0 & 0 & $1(2)$ \\
\hline To refine research question & $1(25)$ & 0 & 0 & 0 & $1(2)$ \\
\hline $\begin{array}{l}\text { To make the review more relevant for target } \\
\text { audience }\end{array}$ & $2(50)$ & 0 & $8(62)$ & 0 & $10(20)$ \\
\hline To understand clinical perspective & 0 & $1(17)$ & 0 & $1(4)$ & $2(4)$ \\
\hline Unspecified & 0 & $4(67)$ & $1(7)$ & $27(96)$ & $32(63)$ \\
\hline \multicolumn{6}{|l|}{ Effect of SI mentioned by authors (\% of SI) } \\
\hline Substantial or positive effect & $2(50)$ & $4(67)$ & $11(85)$ & 0 & $17(33)$ \\
\hline Negative effect & 0 & 0 & 0 & 0 & 0 \\
\hline No effect mentioned & $2(50)$ & $2(33)$ & $2(15)$ & $28(100)$ & $34(67)$ \\
\hline $\begin{array}{l}\text { Explicit encouragement for involving stakeholders } \\
\text { in further studies (\% of reviews) }\end{array}$ & 0 & $1(3)$ & $1(3)$ & $1(3)$ & $3(2)$ \\
\hline
\end{tabular}

CRD, databases of the University of York, Center for Reviews and Dissemination; RR, rapid review; SR, systematic review.

facilitate stakeholder engagement in other review types, for example in systematic reviews.

One limitation of this study is the low response rate to our emails by contact authors. Given the fact that nearly half of our emails to study authors remained unanswered or could not be sent, the rate of unmentioned stakeholder involvement might still be higher than our numbers suggest. Of note, there was no considerable difference between systematic reviews and rapid reviews in the percentage of unmentioned stakeholder involvement.

Although our search is not very recent this article highlights the current situation and there is a call for action. Of course, an updated assessment might be needed in the years following.

Although when using a broad definition of the term 'stakeholder' including everyone with a particular interest in the research topic (but who are not members of the primary research team), this term was not consistently used by contact authors. In their emails, some authors listed peer reviewers as stakeholders or one author erroneously mentioned members of the research team, who performed literature research and data extraction as stakeholders. In addition, interdisciplinary knowledge exchange is an important part of evidence-based research, but there is a difference whether experts from other fields were included as researchers in the study team or whether they were considered as stakeholders. We did not count any experts or peer reviewers as stakeholders. Furthermore, discussion is needed, whether the funding body of a review might contribute as a stakeholder and how a potentially associated conflict of interest could be avoided.

The reported involvement of stakeholders corresponded with Cottrell et al who mentioned that stakeholders might contribute to different study types and evidence phases. ${ }^{142}$ Based on, Keown et al ${ }^{143}$ concluded, that stakeholder involvement led to an increased relevance and depth of review findings, more clarity in defining research questions, broader dissemination of their results and increased awareness of target groups. Although they mentioned that this engagement process required flexibility and might be resource-intensive and time-intensive, they nevertheless concluded that involving stakeholders facilitated implementation and should be indispensable for future research.

Although the overall proportion of stakeholder involvement has not yet increased prominently in the past few years, there have still been considerable efforts in creating 
standardised procedures for involving stakeholders in evidence synthesis. Keown et al identified five opportunities in the systematic review process, where potential stakeholders could be engaged on a regular base. ${ }^{143}$ The CRD rapid reviews included were mainly performed by Health Quality Ontario (Canada) and routinely held expert panels, including physicians, caregivers and sometimes, consumer representatives and professional organisations. The fact that they included stakeholders on a regular basis might confirm, what Keown et $a l^{143}$ had already suggested: the engagement of audience members interested in or affected by the investigated topic definitively resulted in more benefits than limitations. We, therefore, suggest that future researcher involve stakeholders more broadly in the process of evidence synthesis, to increase the relevance and acceptance of the knowledge transfer. One example of an organisation ensuring that stakeholders are involved in research is the James Lind Alliance (http://www.jla.nihr.ac.uk).

In future, the reporting of stakeholder involvement should be improved and its effects better evaluated and communicated. Stakeholder engagement could also be included in reporting checklists of all review types.

Acknowledgements We are indebted to Julia Kreis and Aline Flatz for reviewing the protocol and our thanks go to Sarah Haile for generating the random lists. Parts of this work have been presented at the Global Evidence Summit September 2017 in Cape Town, SA.

Contributors All authors conceived and designed the study. JF collected and interpreted the data and essentially contributed to the writing of the manuscript. MAP and MM supervised the overall research and critically revised the manuscript. All authors approved the final manuscript.

Funding The authors have not declared a specific grant for this research from any funding agency in the public, commercial or not-for-profit sectors.

Competing interests None declared.

Patient consent for publication Not required.

Provenance and peer review Not commissioned; externally peer reviewed.

Data availability statement № data are available.

Open access This is an open access article distributed in accordance with the Creative Commons Attribution Non Commercial (CC BY-NC 4.0) license, which permits others to distribute, remix, adapt, build upon this work non-commercially, and license their derivative works on different terms, provided the original work is properly cited, appropriate credit is given, any changes made indicated, and the use is non-commercial. See: http://creativecommons.org/licenses/by-nc/4.0/.

\section{REFERENCES}

1. Khangura S, Konnyu K, Cushman R, et al. Evidence summaries: the evolution of a rapid review approach. Syst Rev 2012;1:10.

2. Page MJ, Shamseer L, Altman DG, et al. Epidemiology and reporting characteristics of systematic reviews of biomedical research: a cross-sectional study. PLoS Med 2016;13:e1002028.

3. Jadad AR, Cook DJ, Jones A, et al. Methodology and reports of systematic reviews and meta-analyses: a comparison of Cochrane reviews with articles published in paper-based journals. JAMA 1998;280:278-80.

4. Hopewell S, Clarke MJ, Lefebvre C, et al. Handsearching versus electronic searching to identify reports of randomized trials. Cochrane Database Syst Rev 2007;24.

5. Ganann R, Ciliska D, Thomas H. Expediting systematic reviews: methods and implications of rapid reviews. Implementation Sci 2010;5.

6. Watt A, Cameron A, Sturm L, et al. Rapid versus full systematic reviews: validity in clinical practice? ANZ J Surg 2008;78:1037-40.
7. Tricco AC, Antony J, Zarin W, et al. A scoping review of rapid review methods. BMC Med 2015;13:224.

8. Watt A, Cameron A, Sturm L, et al. Rapid reviews versus full systematic reviews: an inventory of current methods and practice in health technology assessment. Int $J$ Technol Assess Health Care 2008;24:133-9.

9. Hailey DM. Health technology assessment in Canada: diversity and evolution. Med J Aust 2007;187:286-8.

10. Mallery C, Ganachari D, Fernandez J, et al. Innovative methods in Stakeholder engagement: an environmental scan. Rockville, MD: Agency for Healthcare Research and Quality, 2012.

11. Concannon TW, Fuster M, Saunders T, et al. A systematic review of stakeholder engagement in comparative effectiveness and patient-centered outcomes research. J Gen Intern Med 2014;29:1692-701.

12. Boote J, Wong R, Booth A. 'Talking the talk or walking the walk?' A bibliometric review of the literature on public involvement in health research published between 1995 and 2009. Health Expect 2015;18:44-57.

13. Kreis J, Puhan MA, Schünemann $\mathrm{HJ}$, et al. Consumer involvement in systematic reviews of comparative effectiveness research. Health Expect 2013;16:323-37.

14. Morley RF, Norman G, Golder S, et al. A systematic scoping review of the evidence for consumer involvement in organisations undertaking systematic reviews: focus on Cochrane. Res Involv Engagem 2016;2.

15. Lohr KN, Steinwachs DM. Health services research: an evolving definition of the field. Health Serv Res 2002;37:7-9.

16. R Core Team. R: a language and environment for statistical computing. Available: https://www.R-project.org/2018

17. Pollock A, Campbell P, Struthers $C$, et al. Stakeholder involvement in systematic reviews: a protocol for a systematic review of methods, outcomes and effects. Res Involv Engagem 2017;3.

18. Shea BJ, Grimshaw JM, Wells GA, et al. Development of AMSTAR: a measurement tool to assess the methodological quality of systematic reviews. BMC Med Res Methodol 2007;7:10.

19. McMaster University Hamilton (Canada). Health evidence 2016. Available: http://www.healthevidence.org [Accessed 06.04.2016].

20. Mc Master Health Forum (McMaster University Hamilton (Canada). Health systems evidence 2016. Available: https://www.healthsy stemsevidence.org [Accessed 06.04.2016.].

21. Moher D, Liberati A, Tetzlaff J, et al. Preferred reporting items for systematic reviews and meta-analyses: the PRISMA statement. $J$ Clin Epidemiol 2009;62:1006-12.

22. Akl EA, Oxman AD, Herrin J, et al. Framing of health information messages. Cochrane Database of Systematic Reviews 2011;22.

23. Bjelakovic G, Gluud LL, Nikolova D, et al. Vitamin D supplementation for prevention of cancer in adults. Cochrane Database Syst Rev 2014;366.

24. Carney T, Myers BJ, Louw J, et al. Brief school-based interventions and behavioural outcomes for substance-using adolescents. Cochrane Database Syst Rev 2014;(2).

25. Chen W, Zhang Y, Li X, et al. Chinese herbal medicine for diabetic peripheral neuropathy. Cochrane Database Syst Rev 2013;10.

26. Cheuk Daniel KL, Chiang Alan KS, Lee Tsz L, et al. Vaccines for prophylaxis of viral infections in patients with hematological malignancies. Cochrane Database of Syst Rev 2011;3.

27. Fede G, Germani G, Gluud C, et al. Propylthiouracil for alcoholic liver disease. Cochrane Database Syst Rev 2011;79.

28. Fonner Virginia A, Denison J, Kennedy Caitlin E, et al. Voluntary counseling and testing (VCT) for changing HIV-related risk behavior in developing countries. Cochrane Database of Syst Rev 2012;9.

29. Garrison SR, Allan GM, Sekhon RK, et al. Magnesium for skeletal muscle cramps. Cochrane Database Syst Rev 2012;173.

30. Jefferson T, Rivetti A, Di Pietrantonj C, et al. Vaccines for preventing influenza in healthy children. Cochrane Database Syst Rev 2012;8.

31. Jin $\mathrm{H}$, Leng $\mathrm{Q}$, Li C, et al. Dietary flavonoid for preventing colorectal neoplasms. Cochrane Database Syst Rev 2012;17.

32. Jorge EC, Jorge EN, El Dib RP, et al. Early light reduction for preventing retinopathy of prematurity in very low birth weight infants. Cochrane Database Syst Rev 2013;91.

33. Junker AE, Als-Nielsen B, Gluud C, et al. Dopamine agents for hepatic encephalopathy. Cochrane Database Syst Rev 2014;30.

34. Karmali KN, Davies P, Taylor F, et al. Promoting patient uptake and adherence in cardiac rehabilitation. Cochrane Database Syst Rev $2014 ; 15$.

35. Kwong Joey SW. Yoga for secondary prevention of coronary heart disease. Cochrane Database Syst Rev 2015;7.

36. Lager KE, Mistri AK, Khunti K, et al. Interventions for improving modifiable risk factor control in the secondary prevention of stroke. Cochrane Database Syst Rev 2014;52. 
37. Martí-Carvajal AJ, Knight-Madden JM, Martinez-Zapata MJ, et al. Interventions for treating leg ulcers in people with sickle cell disease. Cochrane Database Syst Rev 2014;81.

38. Moi JH, Sriranganathan MK, Edwards CJ, et al. Lifestyle interventions for acute gout. Cochrane Database Syst Rev 2013;11.

39. Nava F, Ghilotti F, Maggi L, et al. Biologics, colchicine, corticosteroids, immunosuppressants and interferon-alpha for neuro-Behçet's syndrome. Cochrane Database Syst Rev 2014;12.

40. Njei B, Kongnyuy EJ, Kumar S, et al. Optimal timing for antiretroviral therapy initiation in patients with HIV infection and concurrent cryptococcal meningitis. Cochrane Database Syst Rev 2013;50(11.

41. Charles O I, Nagpal S, Musekiwa A, et al. Home- or communitybased programmes for treating malaria. Cochrane Database Syst Rev 2013;5.

42. Olsen O, Clausen JA, Cochrane Pregnancy and Childbirth Group. Planned Hospital birth versus planned home birth. Cochrane Database Syst Rev 2012;312.

43. Overdevest Gijsbert M, Jacobs W, Vleggeert-Lankamp C, et al. Effectiveness of posterior decompression techniques compared with conventional laminectomy for lumbar stenosis. Cochrane Database Syst Rev2015;3.

44. Peckham EJ, Nelson EA, Greenhalgh J, et al. Homeopathy for treatment of irritable bowel syndrome. Cochrane Database Syst Rev 2013;26.

45. Rahimi-Movaghar A, Amin-Esmaeili M, Hefazi M, et al. Pharmacological therapies for maintenance treatments of opium dependence. Cochrane Database Syst Rev 2013;66.

46. Shields L, Zhou H, Pratt J, et al. Family-centred care for hospitalised children aged 0-12 years. Cochrane Database Syst Rev 2012;45.

47. Smart NA, Marshall BJ, Daley M, et al. Low-Fat diets for acquired hypercholesterolaemia. Cochrane Database Syst Rev 2011;20.

48. Taylor F, Huffman Mark D, Macedo Ana F, et al. Statins for the primary prevention of cardiovascular disease. Cochrane Database Syst Rev2013;1.

49. Taylor Matthew J, Rudkin L, Bullemor-Day P, et al. Strategies for managing sexual dysfunction induced by antidepressant medication. Cochrane Database Syst Rev2013;5.

50. Tejani AM, Wasdell M, Spiwak R, et al. Carnitine for fatigue in multiple sclerosis. Cochrane Database Syst Rev 2012;218.

51. Thomas RE, Lorenzetti D, Spragins W, et al. Mentoring adolescents to prevent drug and alcohol use. Cochrane Database Syst Rev 2011;1.

52. Agarwal R, Goldenberg M, Perry R, et al. The quality of life of adults with attention deficit hyperactivity disorder: a systematic review. Innov Clin Neurosci 2012;9:10-21.

53. Ahmed AA, Alsharief E, Alsharief A. Intensive versus conventional glycemic control: what is best for patients with type 2 diabetes? Diabetes Metab Syndr 2013;7:48-51.

54. Albrecht B, Staiger PK, Hall K, et al. Benzodiazepine use and aggressive behaviour: a systematic review. Aust N Z J Psychiatry 2014;48:1096-114.

55. Bak A, Browne J, Loveday HP, et al. Systematic review of nutritional interventions to prevent healthcare-associated infections in undernourished elderly. Proceedings of the Nutrition Society 2013;72.

56. Blasco MA, Redleaf Ml. Cochlear implantation in unilateral sudden deafness improves tinnitus and speech comprehension: metaanalysis and systematic review. Otol Neurotol 2014;35:1426-32.

57. Bourke L, Homer KE, Thaha MA, et al. Interventions to improve exercise behaviour in sedentary people living with and beyond cancer: a systematic review. Br J Cancer 2014;110:831-41.

58. Chien T-J, Liu C-Y, Chang Y-F, et al. Acupuncture for treating aromatase Inhibitor-Related arthralgia in breast cancer: a systematic review and meta-analysis. The Journal of Alternative and Complementary Medicine 2015;21:251-60.

59. Collins CE, Burrows TL, Bray J, et al. Effectiveness of parentcentred interventions for the prevention and treatment of childhood overweight and obesity in community settings: a systematic review. JBI Database System Rev Implement Rep 2013;11:180-257.

60. Foersch M, Jacobs C, Wriedt S, et al. Effectiveness of maxillary protraction using facemask with or without maxillary expansion: a systematic review and meta-analysis. Clin Oral Investig 2015;19:1181-92.

61. Gibbs M, Winsper C, Marwaha S, et al. Cannabis use and mania symptoms: a systematic review and meta-analysis. European Psychiatry 2015;30.

62. Guerin M, Grimmer K, Kumar S. Community services' involvement in the discharge of older adults from hospital into the community. Int J Integr Care 2013;13:e032.
63. $\mathrm{MB} \mathrm{H}, \mathrm{Xu} \mathrm{H}, \mathrm{Bai} \mathrm{PD}$, et al. Obesity has multifaceted impact on biochemical recurrence of prostate cancer: a dose-response metaanalysis of 36,927 patients. Medical Oncology 2014;31.

64. Johantgen M, Fountain L, Zangaro G, et al. Comparison of labor and delivery care provided by certified nurse-midwives and physicians: a systematic review, 1990 to 2008 . Women's Health Issues 2012;22:e73-81.

65. Lankhaar JAC, de Vries WR, Jansen JACG, et al. Impact of overt and subclinical hypothyroidism on exercise tolerance: a systematic review. Res Q Exerc Sport 2014;85:365-89.

66. Llewellyn A, Simmonds M, Owen CG, et al. Childhood obesity as a predictor of morbidity in adulthood: a systematic review and metaanalysis. Obes Rev 2016;17:56-67.

67. Maglione MA, Das L, Raaen L, et al. Safety of vaccines used for routine immunization of US children: a systematic review. Pediatrics 2014;134:325-37.

68. Matsuda A, Yamaoka K, Tango T, et al. Effectiveness of psychoeducational support on quality of life in early-stage breast cancer patients: a systematic review and meta-analysis of randomized controlled trials. Quality of Life Research 2014;23:21-30.

69. Panagioti M, Gooding PA, Triantafyllou K, et al. Suicidality and posttraumatic stress disorder (PTSD) in adolescents: a systematic review and meta-analysis. Soc Psychiatry Psychiatr Epidemiol 2015;50:525-37.

70. Rodgers M, Asaria M, Walker S, et al. The clinical effectiveness and cost-effectiveness of low-intensity psychological interventions for the secondary prevention of relapse after depression: a systematic review. Health Technol Assess 2012;16:1-129.

71. Rolka EJ, Silverman MJ. A systematic review of music and dyslexia. The Arts in Psychotherapy 2015;46:24-32.

72. Rozet F, Bastide $\mathrm{C}$, Beuzeboc $\mathrm{P}$, et al. Prise en charge des Tumeurs de la prostate à faible Risque évolutif. Progrès en Urologie 2015;25:1-10.

73. Rush CJ, Campbell RT, Jhund PS, et al. Falling cardiovascular mortality in heart failure with reduced ejection fraction and implications for clinical trials. JACC Heart Fail 2015;3:603-14.

74. Scott IC, Tan R, Stahl D, et al. The protective effect of alcohol on developing rheumatoid arthritis: a systematic review and metaanalysis. Rheumatology 2013;52:856-67.

75. Siffredi V, Anderson V, Leventer RJ, et al. Neuropsychological profile of agenesis of the corpus callosum: a systematic review. Dev Neuropsychol 2013;38:36-57.

76. Sipe TA, Finnie RKC, Knopf JA, et al. Effects of mental health benefits legislation: a community guide systematic review. $A m \mathrm{~J}$ Prev Med 2015;48:755-66.

77. Te Morenga L, Mallard S, Mann J. Dietary sugars and body weight: systematic review and meta-analyses of randomised controlled trials and cohort studies. BMJ 2012;346:e7492.

78. Tricco AC, Antony J, Khan PA, et al. Safety and effectiveness of dipeptidyl peptidase- 4 inhibitors versus intermediate-acting insulin or placebo for patients with type 2 diabetes failing two oral antihyperglycaemic agents: a systematic review and network metaanalysis. BMJ Open 2014;4:e005752.

79. Vasconcellos F, Seabra A, Katzmarzyk PT, et al. Physical activity in overweight and obese adolescents: systematic review of the effects on physical fitness components and cardiovascular risk factors. Sports Medicine 2014;44:1139-52.

80. Wang Z. Age-Dependent decline of association between obesity and mortality: a systematic review and meta-analysis. Obes Res Clin Pract 2015;9:1-11.10.1016/j.orcp.2014.01.006

81. Wu S, Cohen D, Shi Y, et al. Economic analysis of physical activity interventions. Am J Prev Med 2011;40:149-58.

82. Canadian Agency for Drugs and Technologies in Health. Sedation and anesthesia options for diagnostic procedures: a review of clinical effectiveness and guidelines. Ottawa (ON: Canadian Agency for Drugs and Technologies in Health, 2015.

83. Attree P, French B, Milton B, et al. The experience of community engagement for individuals: a rapid review of evidence. Health Soc Care Community 2011;19:250-60.

84. Barry MM, D'Eath M, Sixsmith J. Interventions for improving population health literacy: insights from a rapid review of the evidence. J Health Commun 2013;18:1507-22.

85. Beall RF, Baskerville N, Golfam M, et al. Modes of delivery in preventive intervention studies: a rapid review. Eur J Clin Invest 2014;44:688-96.

86. Beck CR, Sokal R, Arunachalam N, et al. Neuraminidase inhibitors for influenza: a review and public health perspective in the aftermath of the 2009 pandemic. Influenza Other Respi Viruses 2013;7-14-24. 
87. Boyce T, Holmes A. Addressing health inequalities in the delivery of the human papillomavirus vaccination programme: examining the role of the school nurse. PLoS One 2012;7:e43416.

88. Brunton G, Paraskeva N, Caird J, et al. Psychosocial predictors, assessment, and outcomes of cosmetic procedures: a systematic rapid evidence assessment. Aesthetic Plast Surg 2014;38:1030-40.

89. Butow P, Price MA, Shaw JM, et al. Clinical pathway for the screening, assessment and management of anxiety and depression in adult cancer patients: Australian guidelines. Psychooncology 2015;24:987-1001.

90. Costello RB, Lentino CV, Boyd CC, et al. The effectiveness of melatonin for promoting healthy sleep: a rapid evidence assessment of the literature. Nutr J 2014;13.

91. Crawford C, Lee C, Bingham J, et al. Sensory art therapies for the self-management of chronic pain symptoms. Pain Medicine 2014;15:S66-S75.

92. Crawford C, Lee C, May T, et al. Physically oriented therapies for the self-management of chronic pain symptoms. Pain Medicine 2014;15:S54-S65.10.1111/pme.12410

93. Dorresteijn PM, Ipenburg NA, Murphy KJ, et al. Rapid systematic review of normal audiometry results as a predictor for benign paroxysmal positional vertigo. Otolaryngol Head Neck Surg 2014;150:919-24.

94. Geddes R, Frank J, Haw S. A rapid review of key strategies to improve the cognitive and social development of children in Scotland. Health Policy 2011;101:20-8.

95. Hithersay R, Strydom A, Moulster G, et al. Carer-led health interventions to monitor, promote and improve the health of adults with intellectual disabilities in the community: a systematic review. Res Dev Disabil 2014;35:887-907.

96. Humphreys DK, Ogilvie D. Synthesising evidence for equity impacts of population-based physical activity interventions: a pilot study. International Journal of Behavioral Nutrition and Physical Activity 2013;10.

97. Jiwa M, McManus A, Dadich A. Continuity of cancer care: where do primary care practitioners fit in? Cancer Forum 2013;37:31-4.

98. Kreindler SA, Cui Y, Metge CJ, et al. Patient characteristics associated with longer emergency department stay: a rapid review. Emerg Med J 2016;33.

99. Kwok E, Konnyu KJ, Skidmore B, et al. Effectiveness and safety of emergency department short-stay units: a rapid review. Canadian Journal of Emergency Medicine 2012;14:S5-S6.

100. Lal S, Adair CE. E-mental health: a rapid review of the literature. Psychiatric Services 2014;65:24-32.

101. Lee C, Crawford C, Schoomaker E, et al. Movement therapies for the self-management of chronic pain symptoms. Pain Medicine 2014;15:S40-S53.

102. Lee C, Crawford C, Swann S, et al. Multimodal, integrative therapies for the self-management of chronic pain symptoms. Pain Medicine 2014;15:S76-S85.

103. Mann R, Gilbody S. Validity of two case finding questions to detect postnatal depression: a review of diagnostic test accuracy. J Affect Disord 2011;133:388-97.

104. McMurran M. Individual-Level interventions for alcohol-related violence: a rapid evidence assessment. Criminal Behaviour and Mental Health 2012;22:14-28.

105. Menear M, Briand C. Implementing a continuum of evidence-based psychosocial interventions for people with severe mental illness: part 1-Review of major initiatives and implementation strategies. The Canadian Journal of Psychiatry 2014;59:178-86.

106. Moe-Byrne T, Chambers D, Harden M, et al. Behaviour change interventions to promote prescribing of generic drugs: a rapid evidence synthesis and systematic review. BMJ Open 2014;4:e004623.

107. Muñoz K, Caballero A, White K. Effectiveness of questionnaires for screening hearing of school-age children: a comprehensive literature review. Int J Audiol 2014;53:910-4.

108. Ndumbe-Eyoh S, Moffatt $\mathrm{H}$. Intersectoral action for health equity: a rapid systematic review. BMC Public Health 2013;13:1056.

109. Saeed S, Golfam M, Beall RF, et al. Effectiveness of individualfocused interventions to prevent chronic disease. Eur J Clin Invest 2014;44:882-90.

110. Trivedy CR, Cooke MW, Visits UR. Unscheduled return visits (URV) in adults to the emergency department (ED): a rapid evidence assessment policy review. Emerg Med J 2015;32:324-9.

111. Yu J, Wang Y, Li Y, et al. The dA Vinci surgical system: a rapid review of the clinical and economic evidence. Value Health 2014;17.

112. Health Technology Assessment Database. Aerobic exercise training in patients with heart failure: a rapid review (structured Abstract), 2015. Available: http://onlinelibrary.wiley.com/o/cochrane/clhta/ articles/HTA-32015000505/frame.html
113. Health Technology Assessment Database. Criteria for referral to home care: a rapid review (structured Abstract), 2015. Available: ://onlinelibrary.wiley.com/o/cochrane/clhta/articles/HTA32015000501/frame.html

114. Health Technology Assessment Database. Physical activity counselling: a rapid review (structured Abstract), 2015. Available: http://onlinelibrary.wiley.com/o/cochrane/clhta/articles/HTA32015000508/frame.htm

115. Health Technology Assessment Database. Care coordination for postacute stroke, chronic obstructive pulmonary disease, and heart failure clients: an economic rapid review (structured Abstract), 2015 Available: http://onlinelibrary.wiley.com/o/cochrane/clhta/articles/ HTA-32015000492/frame.html

116. Health Technology Assessment Database. Sodium restriction in heart failure: a rapid review (structured Abstract), 2015. Available: http://onlinelibrary.wiley.com/o/cochrane/clhta/articles/HTA32015000504/frame.htm

117. Health Technology Assessment Database. Cognitive-Behavioural therapy for anxiety and depression in patients with chronic obstructive pulmonary disease (COPD): a rapid review (structured Abstract), 2015. Available: http://onlinelibrary.wiley.com/o/cochrane/ clhta/articles/HTA-32015000486/frame.html

118. Health Technology Assessment Database. Communication of discharge instructions: a rapid review (structured Abstract), 2015. Available: http://onlinelibrary.wiley.com/o/cochrane/clhta/articles/ HTA-32015000500/frame.htm

119. Health Technology Assessment Database. Prophylactic antibiotics for individuals with chronic obstructive pulmonary disease (COPD): a rapid review (structured Abstract), 2015. Available: http://onlinelibrary.wiley.com/o/cochrane/clhta/articles/HTA32015000489/frame.htm

120. Health Technology Assessment Database. Respiratory therapy services in home care for individuals with chronic obstructive pulmonary disease (COPD): a rapid review (structured Abstract), 2015. Available: http://onlinelibrary.wiley.com/o/cochrane/clhta/ articles/HTA-32015000491/frame.htm

121. Health Technology Assessment Database. Exercise programs after pulmonary rehabilitation for patients with chronic obstructive pulmonary disease (COPD): a rapid review (structured Abstract), 2015. Available: http://onlinelibrary.wiley.com/o/cochrane/clhta/ articles/HTA-32015000488/frame.html

122. Baidoobonso S. Effect of supportive interventions on informal caregivers of people at the end of life: a rapid review (structured Abstract), 2014. Available: http://onlinelibrary.wiley.com/o/cochrane/ clhta/articles/HTA-32015000095/frame.html

123. Brener S. Optimal timing to begin an active rehabilitation program after a hip fracture: a rapid review (structured Abstract), 2013. Available: http://onlinelibrary.wiley.com/o/cochrane/clhta/articles/ HTA-32014001040/frame.htm

124. Brener S. Effectiveness and safety of thrombolytics for the treatment of ischemic stroke: a rapid review (structured Abstract), 2013. Available: http://onlinelibrary.wiley.com/o/cochrane/clhta/ articles/HTA-32014001030/frame.htm

125. Bungay $\mathrm{H}$, Vella-Burrows $\mathrm{T}$. The effects of participating in creative activities on the health and well-being of children and young people: a rapid review of the literature. Perspect Public Health 2013:133:44-52.

126. Ghazipura M. Optimal timing for antibiotic administration in patients with community-acquired pneumonia: a rapid review (structured Abstract), 2013. Available: http://onlinelibrary.wiley.com/o/cochrane/ clhta/articles/HTA-32014001051/frame.html

127. Ghazipura M. Community versus inpatient rehabilitation in hip fracture patients: a rapid review (Structured abstract). Health Technology Assessment Database [Internet], 2013. Available: http://onlinelibrary.wiley.com/o/cochrane/clhta/articles/HTA32014001045/frame.htm

128. Ghazipura M. Cardiovascular and aerobic exercise in postacute stroke patients: a rapid review (structured Abstract), 2015. Available: http://onlinelibrary.wiley.com/o/cochrane/clhta/articles/ HTA-32015000494/frame.html

129. Ghazipura M. Home-Based versus centre-based rehabilitation for community-dwelling postacute stroke patients: an economic rapid review (structured Abstract), 2015. Available: http://onlinelibrary.wiley.com/o/cochrane/clhta/articles/HTA32015000493/frame.html

130. Kabali C. Self-Management and educational interventions in the postacute stroke population: a rapid review (structured Abstract), 2015. Available: http://onlinelibrary.wiley.com/o/cochrane/clhta/ articles/HTA-32015000498/frame.html

131. Lambrinos A. Preoperative consultation: a rapid review (structured Abstract). health technology assessment database, 2014. Available: 
http://onlinelibrary.wiley.com/o/cochrane/clhta/articles/HTA32014001064/frame.htm

132. Lambrinos A. Medication reconciliation at discharge: a rapid review (structured Abstract). health technology assessment database, 2015. Available: http://onlinelibrary.wiley.com/o/cochrane/clhta/ articles/HTA-32015000507/frame.html

133. Lambrinos A. Home-Based exercise programs in heart failure: a rapid review (structured Abstract). health technology assessment database, 2015. Available: http://onlinelibrary.wiley.com/o/ cochrane/clhta/articles/HTA-32015000506/frame.html

134. Ling D. Role of screening for respiratory syncytial virus or influenza and empirical antiviral treatment for patients with communityacquired pneumonia: a rapid review (structured Abstract). health technology assessment database, 2013. Available: http://onlinelibrary.wiley.com/o/cochrane/clhta/articles/HTA32014001055/frame.html

135. McCurdy BR. Inhospital physiotherapy for acute exacerbations of chronic obstructive pulmonary disease (AECOPD): a rapid review (structured Abstract). health technology assessment database, 2013. Available: http://onlinelibrary.wiley.com/o/cochrane/clhta/ articles/HTA-32014001027/frame.html

136. McCurdy BR. Action plans for individuals with chronic obstructive pulmonary disease (COPD): a rapid review (structured Abstract). health technology assessment database, 2013. Available: http://onlinelibrary.wiley.com/o/cochrane/clhta/articles/HTA32014001026/frame.htm

137. Miani C, Ball S, Pitchforth E, et al. Organisational interventions to reduce length of stay in hospital: a rapid evidence assessment (structured Abstract). health technology assessment database, 2014. Available: http://onlinelibrary.wiley.com/o/cochrane/clhta/ articles/HTA-32014001458/frame.html

138. Nikitovic M. Intensity of rehabilitation after hip fracture: a rapid review (structured Abstract). health technology assessment database, 2013. Available: http://onlinelibrary.wiley.com/o/ cochrane/clhta/articles/HTA-32014001044/frame.html

139. Schaink $A$. The effectiveness of statins for primary prevention: a rapid review (structured Abstract). health technology assessment database, 2013. Available: http://onlinelibrary.wiley.com/o/ cochrane/clhta/articles/HTA-32014001037/frame.html

140. Wang M. Airway clearance techniques for patients with stable chronic obstructive pulmonary disease (COPD): a rapid review (structured Abstract). health technology assessment database, 2015. Available: http://onlinelibrary.wiley.com/o/cochrane/clhta/ articles/HTA-32015000487/frame.html

141. Wang M. Pulmonary rehabilitation in the home versus other settings for individuals with chronic obstructive pulmonary disease (COPD): a rapid review (structured Abstract). health technology assessment database, 2015. Available: http:// onlinelibrary.wiley.com/o/cochrane/clhta/articles/HTA32015000495/frame.html

142. Cottrell E, Whitlock E, Kato E, et al. Defining the benefits of Stakeholder engagement in systematic reviews. Rockville (MD: AHRQ Methods for Effective Health Care, 2014.

143. Keown K, Van Eerd D, Irvin E. Stakeholder engagement opportunities in systematic reviews: knowledge transfer for policy and practice. J Contin Educ Health Prof 2008;28:67-72. 